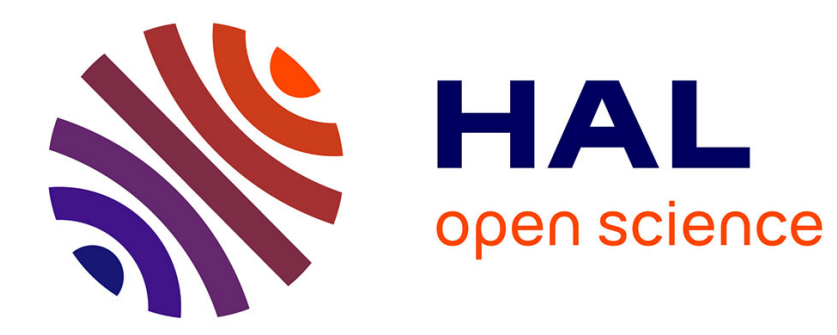

\title{
LTO - SiO2 DEPOSITION IN A STAGNATION FLOW LPCVD SYSTEM
}

\author{
R. Weber, G. Wahl, R. Huber
}

\section{To cite this version:}

R. Weber, G. Wahl, R. Huber. LTO - SiO2 DEPOSITION IN A STAGNATION FLOW LPCVD SYSTEM. Journal de Physique Colloques, 1989, 50 (C5), pp.C5-411-C5-419. 10.1051/jphyscol:1989549 . jpa-00229579

\section{HAL Id: jpa-00229579 https://hal.science/jpa-00229579}

Submitted on 1 Jan 1989

HAL is a multi-disciplinary open access archive for the deposit and dissemination of scientific research documents, whether they are published or not. The documents may come from teaching and research institutions in France or abroad, or from public or private research centers.
L'archive ouverte pluridisciplinaire HAL, est destinée au dépôt et à la diffusion de documents scientifiques de niveau recherche, publiés ou non, émanant des établissements d'enseignement et de recherche français ou étrangers, des laboratoires publics ou privés. 
JOURNAL DE PHYSIQUE

Colloque C5, supplément au $n^{\circ} 5$, Tome 50, mai 1989

LTO - $\mathrm{SiO}_{2}$ DEPOSITION IN A STAGNATION FLOW LPCVD SYSTEM

R. WEBER, G. WAHL and R. HUBER

ASEA Brown Boveri, Corporate Research Heidelberg, D-6900 Heidelberg, F.R.G.

\begin{abstract}
Résumé
Un dispositif à parois froides a basse temperature, avec une configuration de flux d'arrét, est utilisé pour le dépôt de $\mathrm{SiO}_{2}$ sur des plaquettes de silicium, entre $280^{\circ}-400^{\circ} \mathrm{C}$. Les proprietes suivantes des films ont été étudieés: vitesse de dépôt, distribution de l'épaisseur, indice de réfraction, vitesse de corrosion humide, charactérisation chimique par ESCA et infrarouge, charactéristiques electriques en fonction de la température du substrat, de la pression total, du gaz vecteur et du rapport $\mathrm{O}_{2} / \mathrm{SiH}_{4}$.
\end{abstract}

\begin{abstract}
A cold wall low temperature oxide (LTO) process, by a stagnation flow technique for the deposition of device quality $\mathrm{SiO}_{2}$ on silicon wafers at temperatures of $280^{\circ}-400^{\circ} \mathrm{C}$ is reported. The following properties of the $\mathrm{SiO}_{2}$ films were investigated: Growth rate, deposition profile, refractive index, wet etch rate, chemical characterization by XPS, electrical properties and IR - spectra have been studied as function of substrate temperature, reaction pressure, carrier gas and $\mathrm{O}_{2} / \mathrm{SiH}_{4}$ mole ratio.
\end{abstract}

\title{
I. Introduction
}

The growth of thin silicon dioxide layers by chemical vapor deposition (CVD) has become one of the most important methods for semiconductor device processing and has been investigated by several authors $/ 1 /-/ 6 /$. The main advantage of LTO depositions is their considerably lower process temperature as compared to high temperature oxide (HTO: $\mathrm{SiH}_{2} \mathrm{Cl}_{2}+\mathrm{N}_{2} \mathrm{O} ;=850^{\circ} \mathrm{C}$ ) and the tetraethylorthosilicate process (TEOS: $=700^{\circ} \mathrm{C}$ ). Unlike plasma enhanced CVD, LTO processes avoid high concentrations of bonded hydrogen (in the form of $\mathrm{Si}-\mathrm{H}$ and of $\mathrm{OH}$ groups) in the oxides. $\mathrm{H}$-bonds in the $\mathrm{SiO}_{2}$ films can produce recombination centers and cause deep trapping /7/. The LTO process avoids plasma induced surface damage, which can also lead to high H-concentrations /7/. In particular LTO processes with stagnation flow technique attain deposition rates, which exceed the deposition rates of other processes as e.g. LTO processes with LPCVD quartz tubes, by an order of magnitude. Stagnation flow deposition systems with high deposition rates produce advantageously high yields and good film quality. Their low deposition temperature and high deposition rates make $\mathrm{SiO}_{2}$ films suitable for final passivation after aluminium metallization. Furthermore the high deposition rate and the option to use a vacuum loadlock make a throughput as high as in batch systems possible. Especially for R\&D applications these systems provide a number of advantages like quick processing, high efficiency, easy investigation of the reaction products and simplified numerical simulation /8/. In a stagnation flow reactor the deposition results depend mainly on: Gas flow, convection, diffusion and chemical reactions in the gas phase and at the wafer surface. Optimalisation of these parameters is a crucial requirement for manufacturers (reactor design, process control and development) and for users (deposition profile, film properties). This work describes the dependency of the deposition results on variation of the process parameters. 


\section{Experimental}

A specially designed cold wall reactor (Fig.1) was used for these investigations. The reactor consisted of a rotating infra-red heated wafer support and a shower head type gas inlet system. A two stage rotary pump (Leybold TRIVAC $40 \mathrm{BCS}$ ) in connection with a roots blower (Leybold RUVAC 250 wSU) provided the necessary low pressure ( $<5000$ pascal) in the CVD reactor. The flow rates of the reaction gases ( $\mathrm{SiH}_{4}, \mathrm{O}_{2}$ and $\mathrm{N}_{2}$ for inert gas) were adjusted by thermal mass flow controllers. The gas flow was led through a shower head perpendiculary onto the silicon wafer. Four halogene infra-red lamps generated the required wafer temperature, which was stabilized by feedback via a thermocouple and a self optimizing PID Eurotherm power controller. A purge gas was applied to expel reactive gases from the heat module in order to avoid deposition on the hot lamp surfaces. The reactor chamber and the shower head were made from stainless steel, and the wafer support from fused silica.

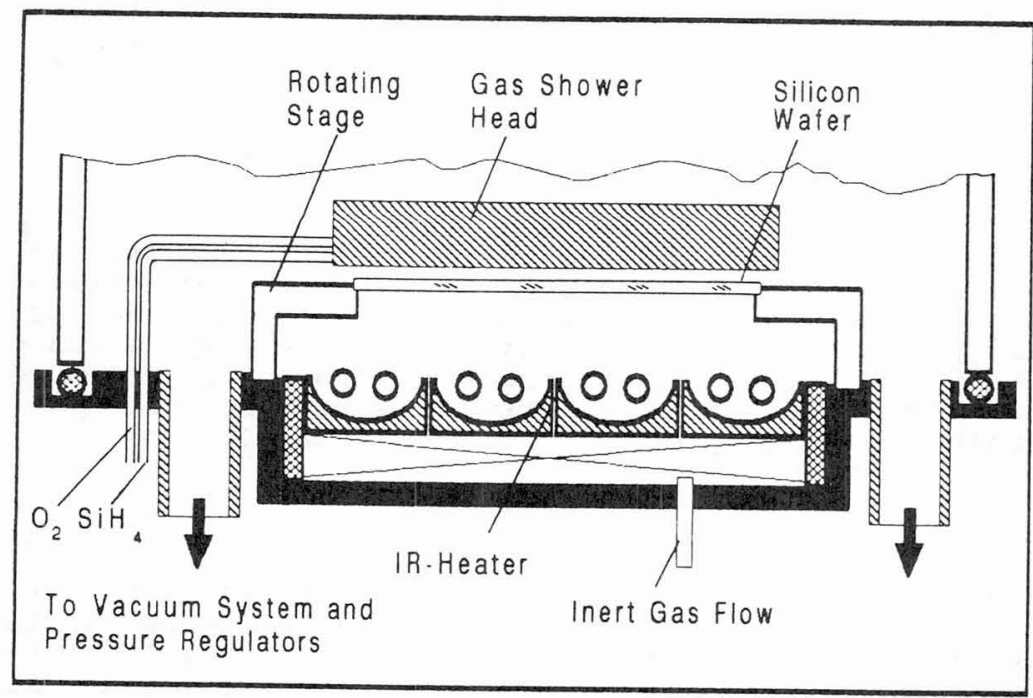

Fig. 1 Arrangement of the LTO deposition reactor

The $\mathrm{SiO}_{2}$ films were deposited onto one-side polished $0.01-0.02 \Omega \mathrm{cm}$ (100) silicon substrates. Electronic grade chemicals (Merck, Selectipur) were used for substrate cleaning. The silicon substrates were cleaned by the following procedure:

- Successive washing (10 minutes each step) in:

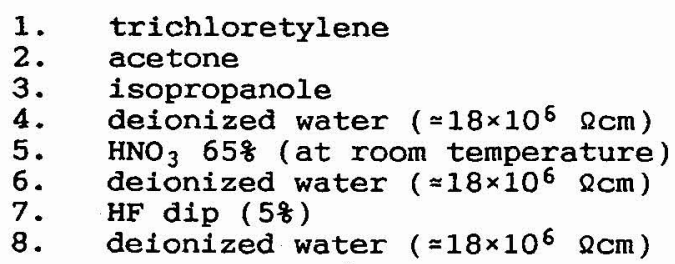

- Treatment in a rinser dryer (15 minutes each step):

9. deionized water $\left(\simeq 18 \times 10^{6} \& \mathrm{~cm}\right)$.

10. hot $\mathrm{N}_{2}$ 


\section{Results and Discussion}

\section{Influence of Temperature}

Deposition experiments were carried out with the following parameters:

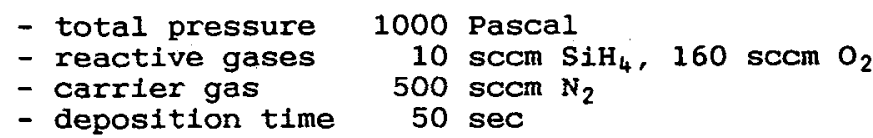

During the heat up time, (approximately $2 \mathrm{~min}$ ) ) reactive gas was led through a bypass and adjusted to a constant flow rate. After the temperature had rissen to the required value, the bypass was closed and the deposition started started. Directly after the deposition process the system was pumped down to $<1 \times 10^{-1}$ Pascal. Afterwards the system was purged with $\mathrm{N}_{2}$ until the wafer was cooled down below $40^{\circ} \mathrm{C}$ and then refilled to atmospheric pressure. Subsequently a new wafer was placed into the reactor and the next deposition could be. started. The dependence of growth rate on the wafer temperature is shown in Fig. 2. In the temperature range between $300^{\circ} \mathrm{C}$ and $370^{\circ} \mathrm{C}$ the deposition rate increases by a rate of $\simeq 0.02 \mathrm{~nm} \mathrm{sec}-1 / \mathrm{C}$ proportionally to the temperature. Above $370^{\circ} \mathrm{C}$ the growth rate vs.temperature curve flattens out.

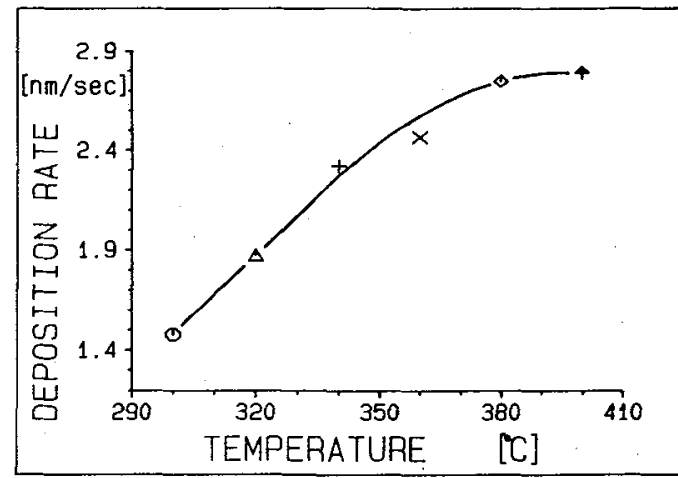

Fig. 2 Deposition rate vs. temperature

\section{Influence of oxygen-to-silane ratio (y)}

The oxygen-to-silane ratio $\gamma$ was varied, while the total gas flow, the pressure, and the temperature was kept constant $\left(720 \mathrm{sccm}, 1000 \mathrm{~Pa}, 400^{\circ} \mathrm{C}\right)$. The results for $\gamma$-values from 1 to 32 are plotted in Fig. 3. For $\gamma$-ratios up to 8 , the growth rate vs. $Y$-curve shows a steep rise; for higher $\gamma$ ratios the growth rate comes to saturation at a value of about $2.9 \mathrm{~nm} / \mathrm{sec}$. The film thickness uniformity deteriorates considerably with decreasing $\gamma$ - values, as is shown in Fig. 4.

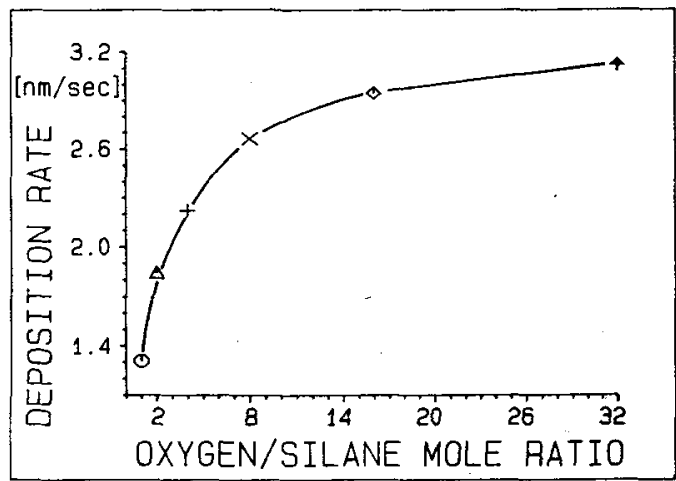

Fig.3 Deposition rate vs. Y 


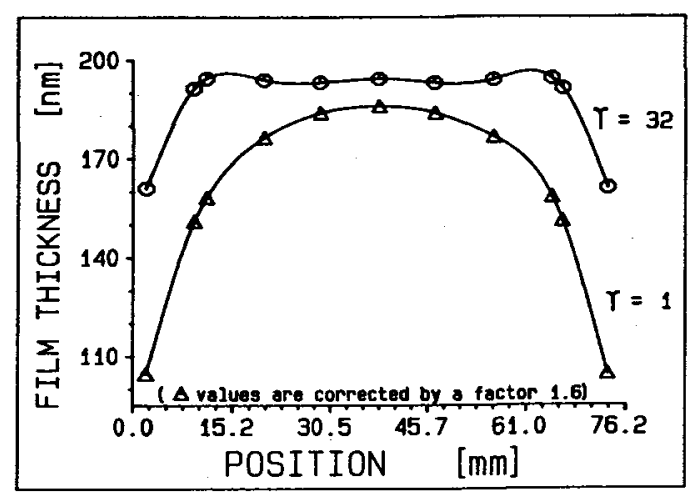

Fig.4 Film thickness profiles for different $\gamma$-values

\section{Pressure Influence}

The deposition rate versus total pressure (with gas flow, wafer temperature and carrier gas flow kept constant) is depicted in Fig. 5; the maximum rate is approximately $3.6 \mathrm{~nm} / \mathrm{sec}$ at $1200 \mathrm{~Pa}$. Fig. 6 shows ellipsometrically measured thickness profiles, for different total pressures. The thickness profiles show the best uniformity $(\approx 2 \%$ deviation from the mean value, within a distance of $9 \mathrm{~mm}$ from the edges) at a pressure of $1200 \mathrm{~Pa}$. Thickness uniformity and growth rate are thus simultaniously optimized. Operation at pressure levels higher than the optimum value (1200 Pa) lead to deteriored thickness profiles. At lower pressures than $800 \mathrm{~Pa}$ the deposition rate becomes small and some particulate contamination can be observed.

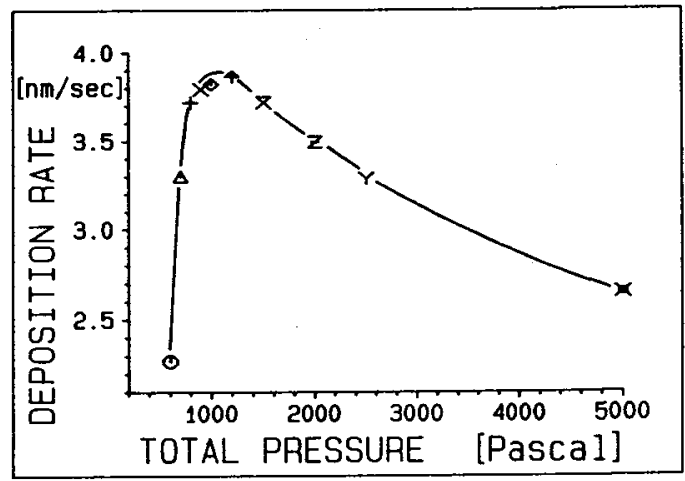

Fig. 5 Deposition rate vs. total pressure

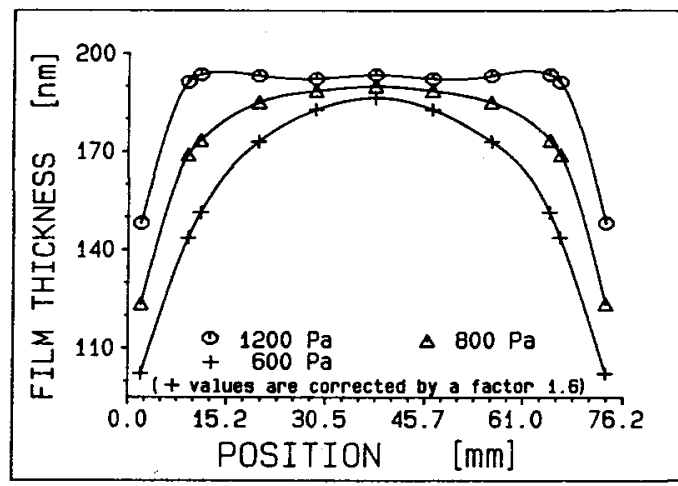

Fig. 6 Ellipsometrically measured thickness profiles for different total pressures 


\section{Influence of Carrier Gas}

The carrier gas flow is another important parameter which effects the deposition rate and particulate contamination. The formation of particulate $\mathrm{SiO}_{2}-$ deposits is well known $/ 9 /$ and can be suppressed with optimized process parameters. In order to reduce the concentration of the reactive gas, $\mathrm{N}_{2}$ was applied as diluting gas. We used highly pure nitrogen $\left(\mathrm{H}_{2} \mathrm{O}\right.$ and $\mathrm{O}_{2}$ contents $<0.1 \mathrm{ppm}$ ) to optimize deposition results and to suppress homogeneous gas phase nucleation. At high flow rates the $\mathrm{S}_{1} \mathrm{O}_{2}$ deposition rate decreases and a film thickness deviation of greater than $12 \%$ from the mean value (measured at a distance of $9 \mathrm{~mm}$ from the edges) occurs. Fig. 7 shows the influence of the carrier gas on the deposition rate. We found that lower particulate contamination of the reactor walls, adequate deposition rates and profiles can be obtained at about $500 \mathrm{sccm}$ carrier gas flow. Examples for $\mathrm{SiO}_{2}$ profiles at different carrier gas flows are shown in Fig. 8 .

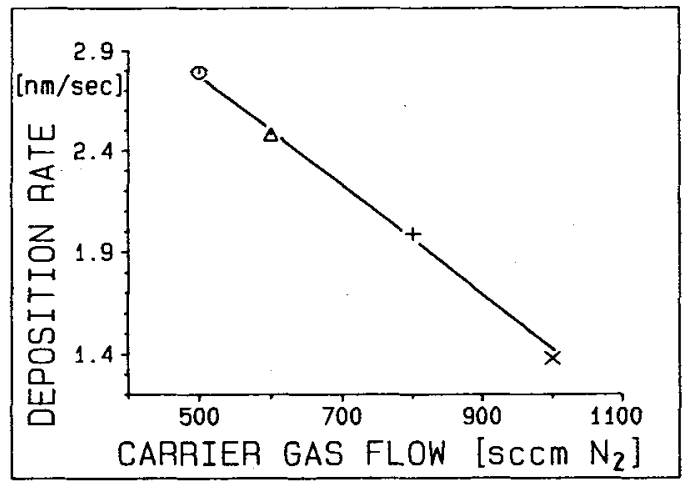

Fig. 7 Deposition rate vs. flow rate of carrier gas

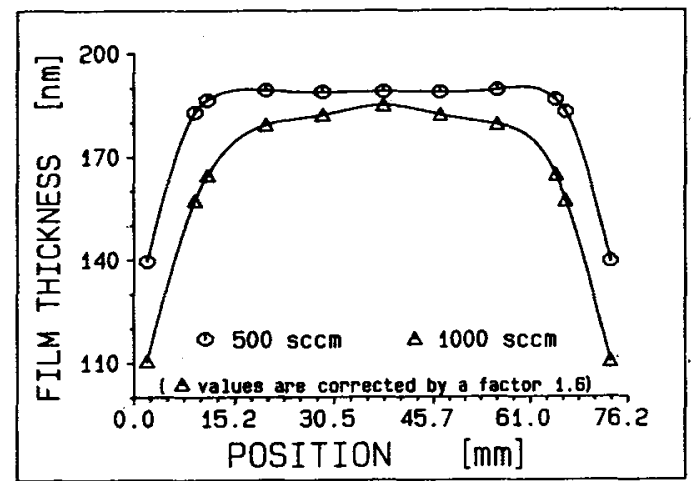

Fig. 8 Thickness uniformity for different carrier gas flows

\section{Showex Head Variation}

The film uniformity depends strongly on the gas flow from the gas inlet shower head. For instance the distance between substrate and gas shower head had a strong impact on the deposition results. A homogeneous distribution of holes over the shower head resulted in a poor uniformity of the layer thickness (Fig. 9a). To compensate this effect one can use an inhomogeneous distribution of holes. The resulting film uniformity is shown in Fig. $9 \mathrm{~b}$. 


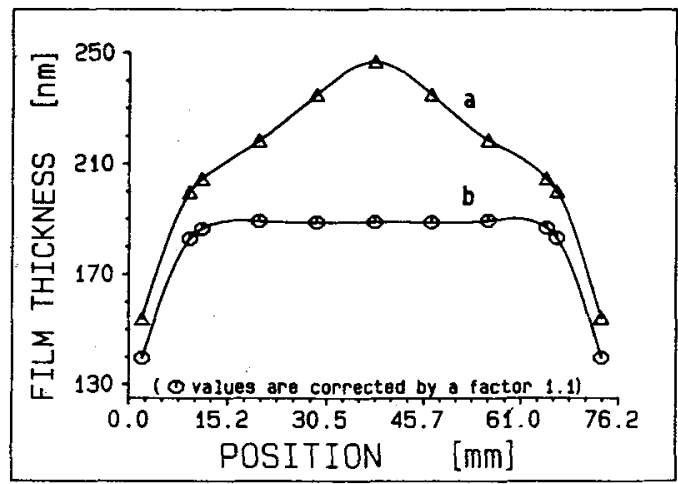

Fig. 9 Thickness profiles for different gas nozzels distribution

\section{Etch Rate}

A sensitive characterization of the silicon dioxide quality is the determination of the etch rate. Chemical structure of the films, mechanical stress, resistivity and breakdown field are in most cases related to the etch properties $/ 10 /$. Etch rates of the $\mathrm{S}_{10} \mathrm{O}_{2}$ films in $1.8 \mathrm{M} \mathrm{HF}$ are nearly constant for all applied deposition temperatures $\left(300^{\circ} \mathrm{C}, 350^{\circ} \mathrm{C}, 400^{\circ} \mathrm{C}\right)$. We found an etch rate of $\approx 3 \mathrm{~nm} / \mathrm{sec}$, which is approximately the fourfold value of the etch rate of thermal oxides. This value is comparable to the case of PECVD films /11/.

\section{Film Composition}

The physical properties of the $\mathrm{SiO}_{2}$ layers were investigated by IR - absorption, X-ray photoelectron spectroscopy (XPS) and ellipsometry. A PerkinElmer 597 spectrometer (wave number $200-4000 \mathrm{~cm}^{-1}$ ) was used for infra-red measurements. The film composition, was determined by XPS (ESCA LAB MK2 V.G. Scientific). IR and $C-V$ measurements were carried out on films deposited onto one-side polished (111) $40-658 \mathrm{~cm}$ wafers. In order to remove surface contaminants like carbon and oxygen, the as-deposited films were sputtered for 30 minutes with argon ions (corresponding to $\approx 30 \mathrm{~nm}$ film depth). After this treatment the observed composition of 31.8 at. $8 \mathrm{~S} 1$ and 68.2 at. $8 \mathrm{O}_{2} \mathrm{cor}-$ responds closely to stoichiometric $\mathrm{SiO}_{2}$. This agrees well with ellipsometric measurements of the refractive index for the $400^{\circ} \mathrm{C}$ sample, which gave a value of 1.462 , close to the value 1.456 of thermal oxide. Fig. 10 shows typical IR-spectra for different deposition temperatures. For a deposition temperature of $400^{\circ} \mathrm{C}$ the $\mathrm{SiO}_{2}$ spectra resemble the spectra from thermally grown $\mathrm{SHO}_{2}$, except of an $\mathrm{O}-\mathrm{H}$ stretching peak at $3620 \mathrm{~cm}^{-1}$. For lower deposition temperatures like $300 \mathrm{C}$ an additional peak appeared at $880 \mathrm{~cm}^{-1}$. This peak is well known as corresponding to $\mathrm{Si-H}$ vibrations /12/. Si-H groups generate localized states within the energy gap of silicon dioxide /13/ and impair the quality of $\mathrm{SiO}_{2}$ films.

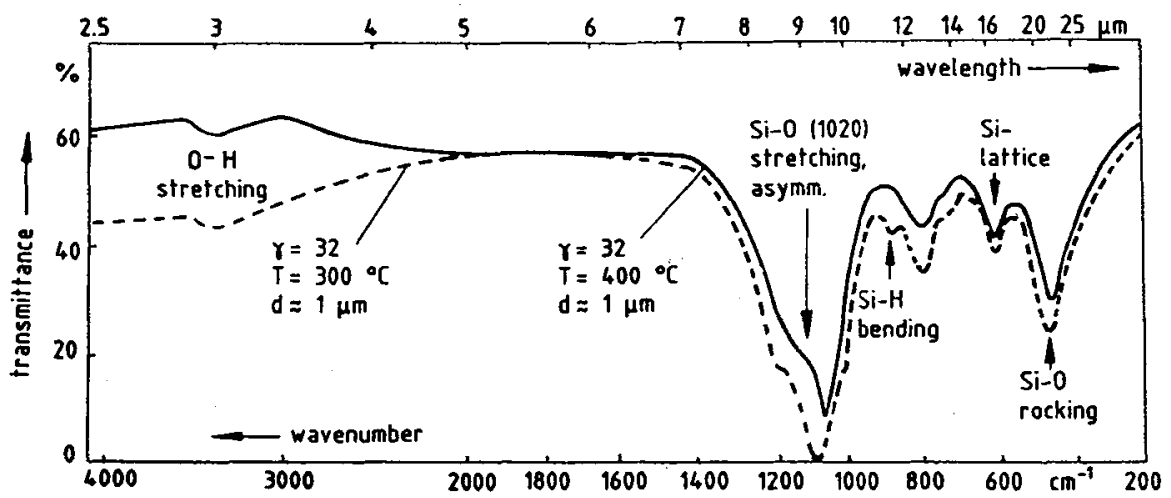

Fig. 10 Infra-red spectra for two different deposition temperatures 
8. Electrical Measurements

(C-V characteristics and dielectric breakdown strength)

MIS capacitors were utilized to characterize the electronic properties of asdeposited and thermally annealed $\left(30 \mathrm{~min}, 450^{\circ} \mathrm{C}\right.$, forming gas) films. Aluminium dots were sputtered onto deposited $\mathrm{SiO}_{2}$ films and structurized by photolithography to form MIS capacitors. Dots with an area of $1.0 \times 10^{-2} \mathrm{~cm}^{2}$ were sputtered on films of about $200 \mathrm{~nm}$ thickness. The depositions were performed on a (100) n-Si substrate with a resistivity of $40-658 \mathrm{~cm}$. A resulting $1 \mathrm{MHz}$ (at room temperature) C-V plot for an as-deposited sample is shown in Fig. 11. A flatband voltage shift of $=-4 \mathrm{~V}$ can be observed, caused by oxide and surface charges. The $\mathrm{C}-\mathrm{V}$ curve shows a small amount of hysteresis this indicates mobile ion arift or occurrence of interface states $/ 14 /-/ 15 /$. After the described anealing procedure the interface damage is evidently reduced. The resulting $\mathrm{C}-\mathrm{V}$ curve (Fig. 12b) is now comparable to the $\mathrm{C}-\mathrm{V}$ characteristics of thermally grown $\mathrm{SiO}_{2}$ (Fig. $\left.12 \mathrm{a}\right)$.

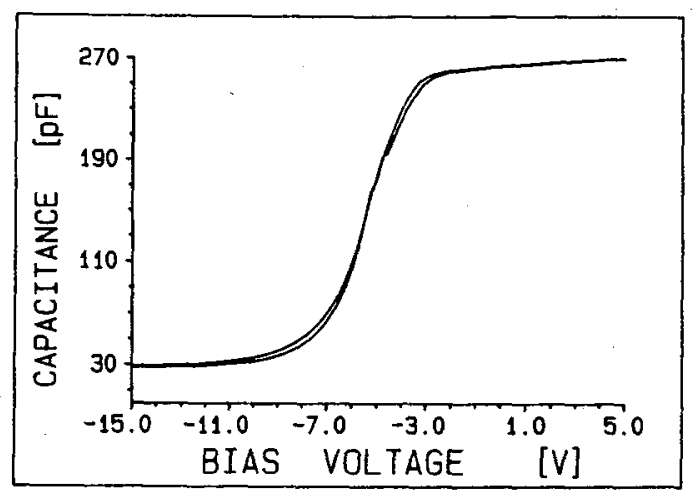

Fig. $11 \mathrm{C}-\mathrm{V}$ curve of a $\mathrm{S}_{1} \mathrm{O}_{2}$ film deposited at $400^{\circ} \mathrm{C}$ (as-deposited). Using the formular $V_{F B}=\phi_{M S}+Q_{F} / C_{I} / 15 /$ and the measured value of $C_{I}$ the density of fixed interface charges was determined to be $Q_{F} / e=9 \times 10^{11} \mathrm{~cm}^{-2}$.

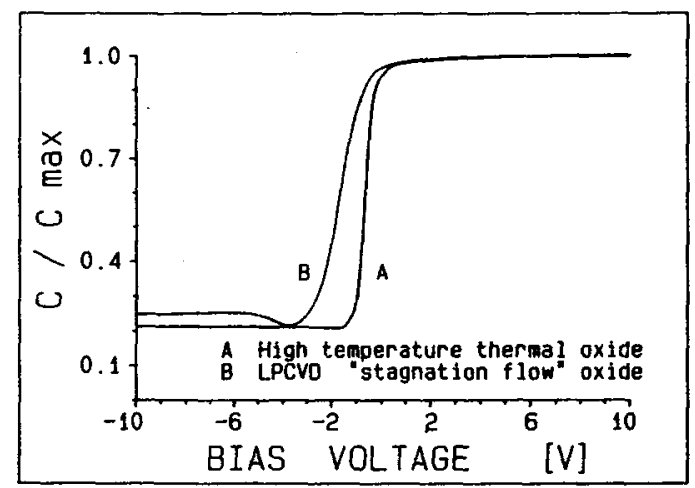

Fig. 12 C-V curves of a post metallization annealed $\mathrm{SiO}_{2}$ film (B) the fixed interface charges (see formular Fig. 11) was determined to be $Q_{F} / e=1.4 \times 1011 \mathrm{~cm}^{-2}$. For comparison a thermal grown $\mathrm{SiO}_{2}$ film is shown in curve (A).

Breakdown data were taken on similar MIS structures with sputtered aluminium dots (area of $1.5 \times 10^{-3} \mathrm{~cm}^{2}$ ). A slowly increasing voltage was applied to the capacitors till they broke down. Typically 70 measurements were taken for each sample. Histograms of the breakdown fields are plotted for two different deposition temperatures $\left(300^{\circ}\right.$ and $400^{\circ} \mathrm{C}$ ) in Fig. 13. The breakdown histograms of the two processes show a shift to higher breakdown voltages at higher deposition temperatures $\left(400^{\circ} \mathrm{C}\right)$. 

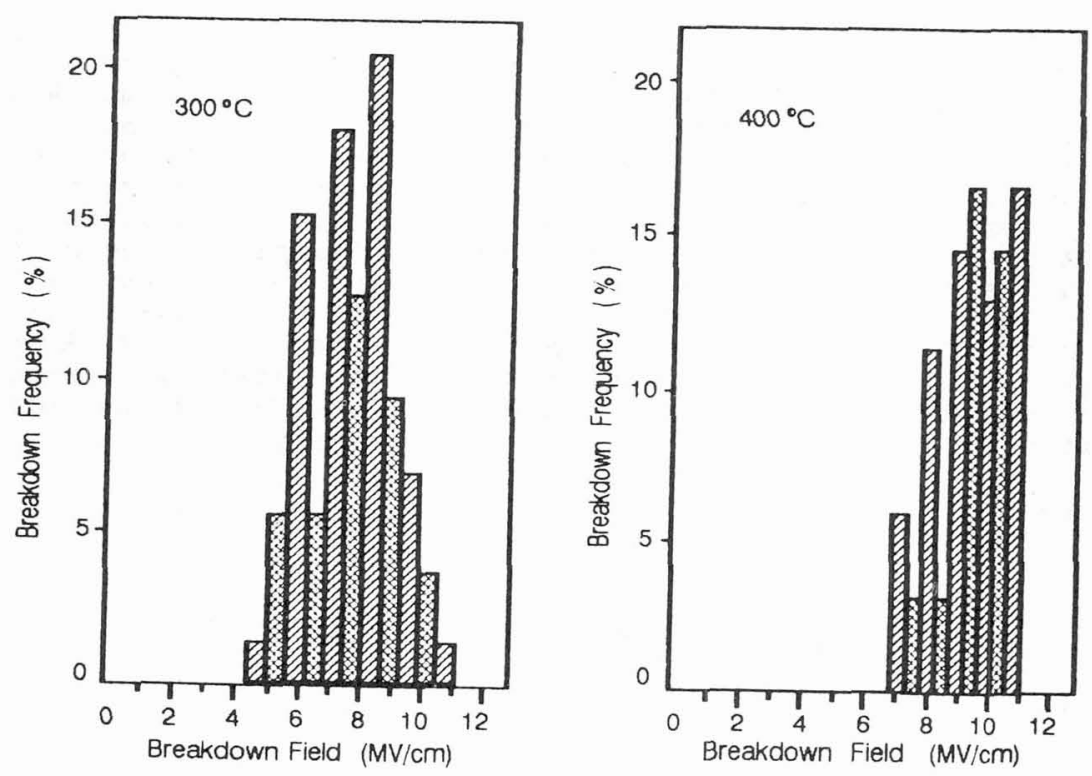

Fig. 13 Breakdown histograms of $\mathrm{S}_{10} \mathrm{O}_{2}$ films deposited at $300^{\circ}$ and $400^{\circ} \mathrm{C}$

\section{Summary and Conclusions}

High-quality low temperature oxide has been deposited at high deposition rates (up to $\simeq 4 \mathrm{~nm} / \mathrm{sec}$ ) by a stagnation flow reactor. The advantages of the stagnation flow gas kinetics, in comparison to diffusion limited processes like quartz tube reactors, are enhanced deposition rates and adequate thickness uniformity $(=2 \%$ deviation from the mean). Breakdown experiments, $C-V$ data, IR-spectra, refractive index and XPS results all demonstrate a good film quality, comparable to thermally grown oxides.

\section{Acknowledgements}

The authors gratefully recognize the technical assistance of J. Seuss and $\mathrm{K}$. Jannsen.

\section{References}

/1/ B.R. Bennett, J.P. Lorenzo, and K. Vaccaro Appl. Phys. Lett. 50, 197 (1987)

/2/ C. Pavelescu, C. Cobianu, and E. Segal Thin Solid Films 140, 261 (1986)

/3/ P.J. Tobin, J.B. Price, and L.M. Campell

J. Electrochem. Soc. 127, No. 10, 2222 (1980)

/4/ G. Wahl

Chemical Vapor Deposition edited by J.M. Blocher, Jr. H.E. Hintermannn, and L.H. Hall, Fifth Interntl. Conf., (1975 Electrochem. Society, Princeton, NY.) 391-406

/5/ J.L. Vossen, W. Kern, Thin. Film Processes Academic Press, Inc. (1978) 
/6/ W. Kern and R.S. Rosler

J. Vac. Sc1. Technol. 14, 1082 (1977)

/7/ Sang S.KIm, D.V. Tsu and G. Lucovsky

J. Vac. Sci. Technol. A 6, 1740 (1988)

/8/ G. Wahl, F. Schmaderer, R. Huber, R. Weber, Chemical Vapor Deposition, Tenth Interntl. Conf., Proc. Electrochem. Soc., 87-8, 42 (1987)

$19 /$ W. Kern and A.W. Fisher

RCA Review, 31, pp. 715-727 (1970)

/10/ W.A. Pliskin and S.J. Zanin Handbook of thin film technology L.I. Maisel and R.Glang, pp. 11-43, McGraw-Hill New York (1970)

/11/ Y. Shioya and M. Maeda

J. Electrochem. Soc. 133, No. 9, 1943 (1986)

112/ W. Kern and R.C. Heim

J. Electrochem. Soc. 117, 562 (1970)

/13/ G. Lucovsky and S.Y. Iin

J. Vac. Sci. Technol. B 3, 1122 (1985)

/14/ G. Barbottin and A.Vapaille, Instabilities in Silicon Devices, pp. 405-439, North-Holland (1986)

/15/ E.H. Nicollian and J.K. Brews, MOS Physics and Technology, pp. 423-491, JOHN WILEY \& SONS (1982) 